maximum, the sea-bed rises suddenly to a depth of only 857 fathoms below the surface.

THE new part of the Mittheilungen of the Hambirg Geographical Society contains several papers of interest. Dr. Sievers concludes the long series of papers describing the results of his journeys in Venezuela with some remarks on his original route map of the Venezuelan Cordilleras, which are accompanied by an admirable reproduction of this map. In addition to this, Herr Frohberg arranges and discusses the barometric results obtained by Dr. Sievers. Dr. Zintgraff describes the Lower Congo from Banana to Vivi, and insists on the importance of the Congo for the exploration of the region behind the German Cameroons protectorate. Herr Weisser gives a fairly complete account of German New Guinea and the Bismarck Archipelago; and Herr Hernsheim does the same for the Marshall Islands.

As a supplement to the Indian Survey Report for $1885-86$, there has just been issued the narrative of the journey of a native explorer, $\mathrm{M}-\mathrm{H}$, through Eastern Nepaul into Southern Tibet, as far as the town of Dingri, and westwards and southwards through Central Nepaul. $\mathrm{M}-\mathrm{H}$ has succeeded in rectifying in many points existing information on the hydrography of the region traversed, and gives many useful notes on its physical geography and its flora, as well as on the people.

\section{OUR ELECTRICAL COLUMN.}

THE additional facts added to our knowledge of electricity in 1887 are not very numerous, but the impetus given to its practical applications was very encouraging. One of the most important scientific discoveries was that of Prof. J. J. Thomson, which formed the subject of the Bakerian Lecture, viz. that sparks in tubes dissociated iodine, bromine, and chlorine. In iodine the dissociation produced at $214^{\circ} \mathrm{C}$. was as much as that effected directly by Victor Meyer at $1570^{\circ} \mathrm{C}$.

PROF. EWING showed that there was apparently no limit to the magnetization of iron in strong magnetic field; when we increased the magnetizing force, and Prof. Roberts Austen showed that it was impossible to separate the elements of alloys by means of electric currents.

IMMENSE improvements have been made in the construction of dynamos, motors, accumulators, and secondary generators, and in consequence electric lighting and working of railways and tramways are upon a commercial and useful stage. Many othe causes besides restrictive legislation have retarded electric lighting in England, but there are now many signs that this usefu industry is in more senses than one about to commence a very bright career.

Several useful constants have been added to our notebooks during the past year. Dr. John Hopkinson is pursuing his examination of the specific inductive capacity of oils and other liquids.

MR. PREECE has determined the coefficient of self-induction of straight iron telegraph aërial wires to $0.005 \times 10^{9}$ centimetre per mile, while that of copper wire is practically nil. He has also measured the current which will just actuate a Bell telephone, and he found it to be $6 \times 10^{-13}$ ampere.

THE application of powerful electric currents to smeltin $y$, as in the Cowles process for producing aluminium, and to weldinr, as proposed by Elihu Thompson, is gaining rapid progress, while the use of enormous dynamos for the deposition of pure copper from impure ores is gaining ground with giant strides. Messrs. Bolton, at Widnes, and Messrs. Vivian, as well as Messrs. Lambert at Swansea, are each depositing from fo:ty to fifty tons of copper per week by currents of from 5000 to 10,000 amperes.

THE Society of Telegraph-Engineers and Electricians has de cided to change its title to that of the Institution of Electrical Engineers-a change for the better. Mr. Graves, the new President, gave an exceedingly interesting address on the industrial importance of electricity, and he brought out the remarkable fact that there are at least 300,000 persons in the United Kingdom depending upon electrical industry for their daily bread.

SOME of our prominent workers in the field of electricity, such as Lord Rayleigh, Sir William Thomson, and Prof. Hughes, are conspicuous by their absence during the past year, although the two former have been by no means idle in other directioas.

\section{A NOTE ON VALENCY, ESPECIALLY AS DEFINED BY HELMHOLTZ,}

VERY little has been either said or written of late on the subject of valency - not because the topic is admitted to be exhausted, nor because our views can be regarded as reposing on a fixed basis of fact, but more I believe on account of the feeling being almost universally entertained that little is to be gained by continuing the discussion from our present standp int.

My purpose in this note is to call attention to the extreme importance of reopening the discussion on account of the intimate bearing that it has on the work in which the Electrolysis Committee, jointly appointed by Sections $A$ and $B$, are now engaged; and to urge that it is time that the gage thrown down by Helmholtz in the Faraday Lecture (Chem. Soc. Trans., I88I, p. 277) was uplifted by chemists.

We are told by Helmholtz that it is a necessary deduction from the fundamental law of electrolysis established by Fara. day, that definite, as it were atomic, charges of electricity are associated with the atoms of matter; that, in fact, a monad bears a single charge, a dyad two, a triad three; and that when combination occur; the charges are still retained by the atoms but neutralize each other- "the atons cling to their charges, and opposite electric charges cling to each other." I cannot help thinking, however, that Helmholtz deprives his statement of much of its force and simplicity by adding: "But I do not suppose that other molecular forces are excluded, working directly from atom to atom." $\mathrm{He}$ is led to do this apparently by being aware of the distinction which it is usual to draw between atomic and m slecular compounds. The attempt should at all events be made-and in my paper on "Residual Affinity" I have already ventured the first step -to include both classes of compounds, molecular as well as atomic, in the discussion; indeed it is somewhat difficult to reconcile the passage above quoted with the following statement which occurs previously in the lecture: "The law of the conservation of energy requires that the electromotive force of every cell must correspond exactly with the $t$, tal amount of chemical forces brought into play, not only the mutual affinities of the ions, but also those minor molecular attractions produced by the waler and other constituents of the fluid." The italics are mine. But if the "minor molecular attractions" contribute to the electromotive force of the cell, then conversely these also will have to be overcome in effecting electrolysis, and are as much to be reckoned as are the "mutual affinities of the ions" :

It is obvious that if it should prove possible to decide what nu nber of charges are necessarily associated with any particular atom, the conception of valency will have acquire $A$ a definiteness which cannot possibly be attached to it as long as the views that have hitherto guided us are adhered to. A decision must involve the discussion of the question of the existence of molecular as distinct from atomic compounds.

To cast the apple of discord without further preface, I would direct attention to the insufficiency of the evidence on which it is usual to rely as proof that nitrogen, for example, is a pentad ; nay more, I would assert that this very evidence should be interpreted a; proof that nitrogen is not a pentad. It is commonly held that the behaviour of the alkyl tetra-substituted derivatives of ammonium is such as to negative the idea that these are "molecular compound " of triad nitrogen, and that it must be assumed that the elements of the binary compound which are added to the ammonia derivative are distributed in the ammonium derivative; for example, that in the formation of tetramethylammonium iodide from tri nethylamine and methyl iodide the methyl and iodine of the iodide part company and separately attach themselves to the nitrozen, thus :-<smiles>CN(C)C</smiles>

But I contend that the properties of tetramethylammonium iodide and hydroxide prove that such is not the case : the iodide, it is well known, can be boiled for hours with the strongest caustic potash solution without undergoing change; there is not a single

I A Paper read by Prof. Henry E. Armstrong, F.R.S., in Section B of the British Association a: Manchester. Communicated by the Author. 